\title{
NOTE
}

\section{Employing Crittercam to study habitat use and behavior of large sharks}

\author{
Michael R. Heithaus ${ }^{1, *}$, Greg J. Marshall ${ }^{2}$, Birgit M. Buhleier ${ }^{2}$, Lawrence M. Dill ${ }^{1}$ \\ ${ }^{1}$ Behavioural Ecology Research Group, Department of Biological Sciences, Simon Fraser University, Burnaby, \\ British Columbia V5A 1S6, Canada \\ ${ }^{2}$ National Geographic Television, Special Projects, Natural History Unit, $114517^{\text {th }}$ St, NW, Washington, DC 20036, USA
}

\begin{abstract}
Investigations of shark habitat use and foraging ecology have been hampered by inaccuracies inherent in many current methods. Although catch rates and acoustic telemetry may be appropriate for studying habitat use at a broad geographic scale, they are often not adequate for finescale determination of habitat use. Also, these techniques cannot provide data on how sharks behave in different habitats or on feeding behavior or social interactions. In this paper, we present a method that allows analysis of shark habitat use using an attached underwater video camera with an integrated time-depth recorder ('Crittercam'), which provides accurate, and continuous habitat use data on a fine geographic scale, as well as a record of shark behavior. Deployments on tiger sharks that were tracked simultaneously $(\mathrm{n}=$ 22) show that habitat use estimates of individual sharks may differ between Crittercam and acoustic tracking data. However, average habitat use measured by acoustic tracking may be accurate if sample sizes are large.
\end{abstract}

KEY WORDS: Acoustic telemetry - Habitat use - Sharks · Behavior · Ecology

Resale or republication not permitted without written consent of the publisher

Investigations of animal habitat use and behavior are important for understanding the ecology of animals and are vital for making informed conservation decisions. In many terrestrial systems and some aquatic systems, it is possible to determine habitat use patterns with considerable accuracy. However, it is much more difficult to quantify habitat use and behavior of large marine animals that may range widely and are not easy to observe directly, such as sharks.

Acoustic telemetry has been used to investigate shark habitat use while most behavioral observations are restricted to captive studies or anecdotal accounts. Acoustic telemetry can be used successfully to determine broad-scale habitat use and to study sharks that remain in a restricted area for a prolonged period (e.g. nursery areas), allowing many individuals to be tracked several times. For example, acoustic tracking of large tiger sharks Galeocerdo cuvier around the

*E-mail: mheithau@sfu.ca
Hawaiian Islands showed that these animals are not strictly coastal and may use relatively shallow offshore banks (Holland et al. 1999). Also, Morrissey \& Gruber (1993) showed that young lemon sharks Negaprion brevirostris selected warm, shallow waters over rocky substrates in North Sound, Bimini, Bahamas.

While acoustic tracking was appropriate for the above-mentioned studies, the technique may not be as useful for investigating habitat use by highly mobile large sharks on a fine scale, particularly where habitats are patchy and there are distinct habitat boundaries. Acoustic tracking is not adequate in such circumstances because position fixes on the animal have a high degree of uncertainty, and it is usually impossible to know the exact location of a tagged shark or the habitat it is occupying if it is near a boundary. In addition, even when shark habitat use can be accurately determined, it is impossible to know the behavior of sharks in various habitats with acoustic tracking.

Studies of shark foraging ecology and feeding behavior are extremely difficult as predation events are rarely witnessed, and most information comes from either anecdotal observations or stomach content analysis. Studies of stomach contents are useful, but they are limited in the hypotheses they can be used to test. For example, when prey types vary in digestion rate, the relative importance of a particular prey type may be under- or over-represented. Also, these studies often cannot identify the habitat in which a shark fed, making definition of critical habitats difficult.

Crittercam is an animal-borne video, audio, and data collection system that can provide data that are impossible to collect with conventional techniques. Crittercam has been used successfully in studies of habitat use, foraging ecology, and behavior of pinnipeds (e.g. Parrish et al. 2000), and has the potential to provide unique insight into the behavior and ecology of large sharks.

Methods. Crittercam: The Crittercam consists of an integrated video camera (either $\mathrm{Hi}-8$ or digital) and

() Inter-Research 2001 


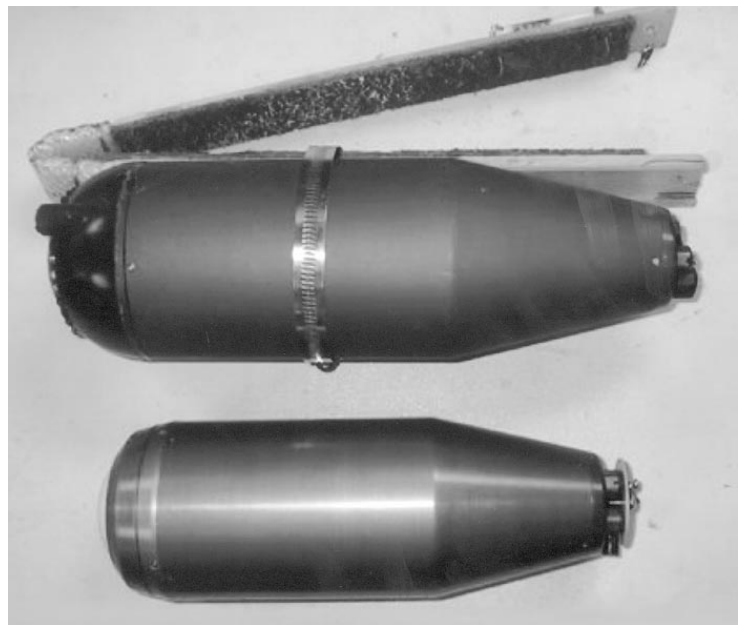

Fig. 1. Hi-8 (top) and digital video (bottom) Crittercam units. A dorsal fin clamp used to attach Crittercams is attached to the Hi-8 unit. Clamps are lined with coarse sandpaper to grip the shark's fin, but do not cause tissue damage or leave any noticeable marks on the dorsal fin

time-depth recorder (TDR) encased in a small hydrodynamic housing (Hi-8: $10.1 \mathrm{~cm}$ diameter, $31.7 \mathrm{~cm}$ in length; digital: $8.8 \mathrm{~cm}$ diameter, $25.4 \mathrm{~cm}$ in length) (Marshall 1998; Fig. 1). The unit contains a computer which allows the camera to be programmed to record continuously or at intermittent intervals for a total recording time of 6 (Hi-8 units) or $2.5 \mathrm{~h}$ (digital units). Temperature and water depth information may be recorded continuously throughout a deployment, up to $7 \mathrm{~d}$, at a user-defined interval (usually every 2 to $7 \mathrm{~s}$ ). Crittercams can also be programmed to release from the animal at a pre-specified time using a burnwire system. In addition, all units incorporate a backup magnesium link that dissolves in seawater. Backup link dissolution times can range from several hours to several days, depending on the thickness of the link used. Crittercams are positively buoyant and float to the surface upon release and are recovered using the signal from a built-in VHF transmitter (MOD-050, 150.0 to $151.0 \mathrm{MHz}$; Telonics, Mesa, AZ, USA) and TR4 VHF receiver (Telonics). During deployments, animals instrumented with Crittercams may be acoustically tracked using a Sonotronics (Tucson, AZ) ultrasonic transmitter $(75.0$ to $76.0 \mathrm{kHz})$ attached to the Crittercam. The maximum detection range for ultrasonic transmitters generally is between 500 and $1000 \mathrm{~m}$, and the VHF signal can be detected at over $20 \mathrm{~km}$.

Crittercam is usually attached to the dorsal fin of a captured shark (Figs. $1 \& 2$ ). The clamp is designed to be held together just posterior to the trailing edge of the dorsal fin and no invasive techniques are required beyond capture. Video recorded using the dorsal fin attachment provides a view of a significant amount of habitat (Fig. 3) and turns rapidly with the shark. The camera is approximately at the sharks' midline, and above the center of mass, which minimizes drag and camera swing. No obvious shark responses to the dorsal fin clamp have been noted.

If sharks cannot be captured, a Crittercam may be attached to the shark with a Floy tag (generally $5 \mathrm{~cm}$ anterior and lateral to the dorsal fin) and a tether. The use of a short tether results in a diminished field of view of the surrounding habitat, as a significant portion of the frame is taken up by the shark's body. If a long tether is used, the Crittercam is configured to 'fly' slightly above the shark, resulting in a large field of view of the habitat around the shark. However, when the shark turns rapidly, the camera is slow to react and is likely to miss recording prey items taken.

Study methods: During a study of tiger shark habitat use, we deployed Crittercams on 40 sharks in Shark Bay, Western Australia, between 1997 and 1999. Our data allow us to test the influence of Crittercams on shark behavior and to determine the accuracy of acoustic tracking in measuring habitat use. The study area in Shark Bay is generally shallow throughout (6 to $15 \mathrm{~m}$ deep), but is intersected by many shallow $(<4.5 \mathrm{~m})$ shoals $\left(\bar{X}=2.3 \mathrm{~km}^{2}\right)$ that are largely covered by seagrasses (see Fig. 1 in Heithaus 2001). There are

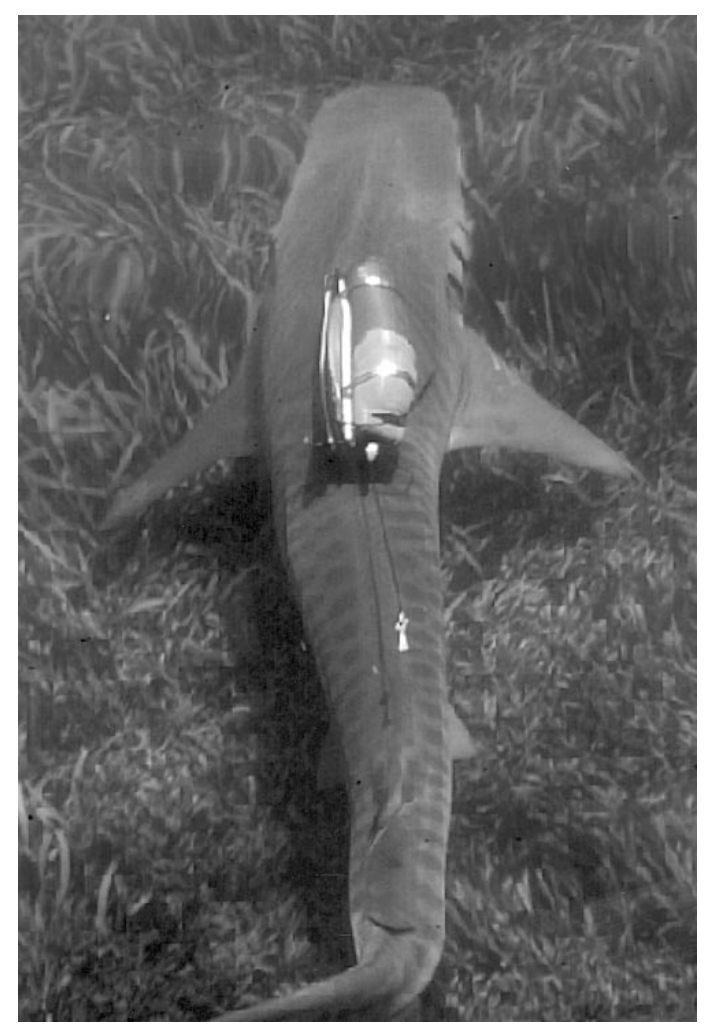

Fig. 2. Crittercam deployed on a $3.2 \mathrm{~m}$ tiger shark 


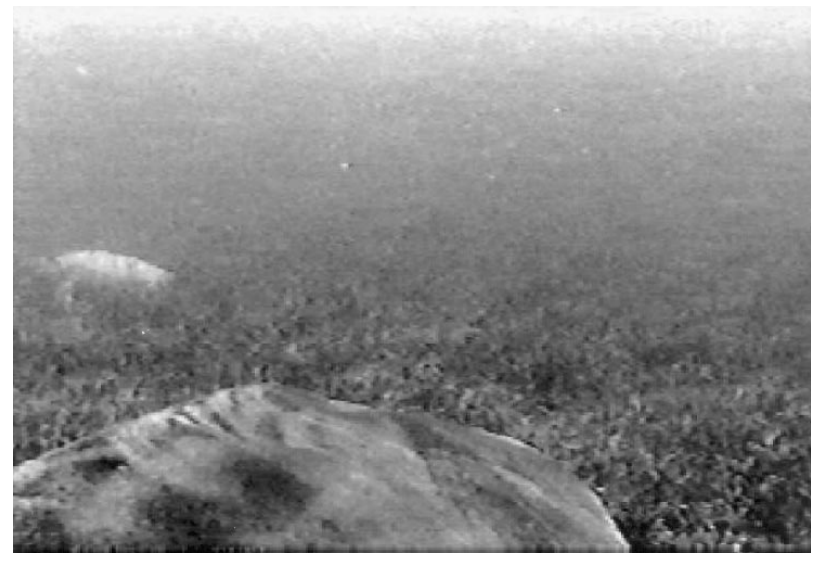

Fig. 3. View of a video frame from a Crittercam deployed with a dorsal fin clamp on a $3.4 \mathrm{~m}$ tiger shark. Notice the surrounding seagrass habitat and the loggerhead sea turtle Caretta caretta in the upper left

relatively distinct boundaries between habitats, making Shark Bay an appropriate location to test the accuracy of acoustic tracking data. Crittercams were attached using Floy tags with short tethers $(n=6)$ or dorsal fin mounts $(n=34)$ on sharks caught by drumline (Heithaus 2001). A subset of these instrumented sharks $(\mathrm{n}=28)$ was tracked acoustically, from a $4.5 \mathrm{~m}$ research vessel using a Sonotronics DH-4 directional hydrophone and USR-5W receiver. During acoustic tracks, the boat generally maintained a distance of 100 to $200 \mathrm{~m}$ from the shark. The position of the tracking boat was frequently changed relative to that of the shark to aid in estimates of shark position and to avoid the possibility that the shark was being 'chased' by the tracking boat. Throughout the track, the boat position (GPS coordinate), estimated distance and direction to the shark, and the habitat the shark was occupying were recorded every $5 \mathrm{~min}$. The habitat that a shark was occupying was estimated using the boat position, estimated distance and direction to the shark, and habitat maps. If the shark was likely in a habitat other than that of the boat, the boat was moved to the estimated position of the shark to determine its habitat once the shark had moved a sufficient distance. Video data were collected continuously on deployments ranging from 15 to $360 \mathrm{~min}$. In addition to Crittercam deployments, 8 other tiger sharks were fitted with VEMCO (Shad Bay, NS) internal acoustic transmitters (V32, 28.5 to $32.8 \mathrm{kHz}$ ) following the methods of Holland et al. (1999) and tracked, according to the above methods, using a VEMCO V11 directional hydrophone and VR60 receiver.

Habitat use was determined from acoustic tracking data by the proportion of 5 min position fixes in each habitat while habitat use was determined from Crittercam using the proportion of time spent in each habitat.
It is important to note that it is not necessary to know the precise location of a shark to determine habitat use from Crittercam. Instead, the habitat an individual is occupying is determined from direct video observations and depth data from the TDR. If determining exact positions of animals was important to a research question, however, Crittercam video data could be used to correct position estimates made from acoustic tracking during a deployment. To make comparisons of habitat use data, data from acoustic tracking and Crittercam were only analyzed for the period where both methods were used concurrently.

Results and discussion. No sharks showed obvious behavioral responses to the Crittercam. Also, the speed of travel by tiger sharks fitted with Crittercam $(\mathrm{n}=40$, $\bar{X}=1.9 \mathrm{~km} \mathrm{~h}^{-1}, \mathrm{SD}=0.73 \mathrm{~km} \mathrm{~h}^{-1}$ ) was not significantly different from that of sharks fitted only with acoustic transmitters $\left(\mathrm{n}=8, \bar{x}=2.0 \mathrm{~km} \mathrm{~h}^{-1}, \mathrm{SD}=0.70 \mathrm{~km} \mathrm{~h}^{-1} ; t=\right.$ $0.27, \mathrm{p}=0.79$ ). Further evidence that tiger sharks are not disturbed by Crittercam comes from the observation of foraging behavior within 30 to 70 min of release in 5 animals. One shark captured an unidentified prey item off the substrate, and another performed a burst swim to capture a prey item (unidentified). Two sharks made course deviations to inspect potential prey, but did not attempt to capture them. Finally, 1 individual fitted with a Crittercam was recaptured on a drumline $70 \mathrm{~min}$ after release.

There was no significant difference in the average proportion of time that sharks spent over shallow seagrass habitats measured by Crittercam $(\bar{x}=0.34, \mathrm{SD}=$ $0.22)$ and estimated from acoustic tracking $(\bar{x}=0.32$, $\mathrm{SD}=0.21$ ) (paired $t$-test for 22 individuals that spent at least $10 \%$ of their time over shoals, $t=1.8, \mathrm{p}=0.09$; Table 1). However, for particular individuals, there were substantial differences between techniques in the measured time spent over shoals. In some cases, Crittercam revealed that a tiger shark spent almost twice as much time in a shallow habitat than was estimated by acoustic tracking (Table 1). Such discrepancies are likely due to errors in estimates of shark position inherent in acoustic tracking techniques. These data suggest that acoustic tracking can provide an accurate measure of average habitat use when many individuals are tracked, but may not be appropriate for understanding the behavior and habitat use of individual sharks. Also, acoustic tracking data may not be appropriate in locations where habitats are more variable and patchy than in Shark Bay (e.g. near reef areas), and the use of Crittercam would be beneficial in such locations. Crittercam may also benefit studies of shark habitat use by allowing sample sizes to be increased substantially, since sharks fitted with Crittercam do not have to be tracked manually. Furthermore, the use of Crittercam deployments without 
Table 1. Comparison of the proportion of time tiger sharks spent over shallow shoals based on acoustic tracking data ( 5 min position fixes) and concurrent Crittercam video data

\begin{tabular}{|llll|}
\hline Shark & Tracking & Crittercam & Ratio \\
\hline 1 & 0.11 & 0.23 & 2.09 \\
2 & 0.77 & 0.92 & 1.19 \\
3 & 0.28 & 0.33 & 1.18 \\
5 & 0.1 & 0.13 & 1.30 \\
8 & 0.13 & 0.1 & 0.77 \\
13 & 0.1 & 0.15 & 1.50 \\
15 & 0.15 & 0.1 & 0.67 \\
18 & 0.17 & 0.21 & 1.24 \\
19 & 0.1 & 0.21 & 2.10 \\
21 & 0.2 & 0.19 & 0.95 \\
22 & 0.1 & 0.2 & 2.00 \\
23 & 0.67 & 0.73 & 1.09 \\
28 & 0.28 & 0.28 & 1.00 \\
30 & 0.4 & 0.46 & 1.15 \\
31 & 0.4 & 0.36 & 0.90 \\
32 & 0.31 & 0.25 & 0.81 \\
33 & 0.39 & 0.32 & 0.82 \\
35 & 0.47 & 0.49 & 1.04 \\
36 & 0.33 & 0.33 & 1.00 \\
37 & 0.8 & 0.78 & 0.98 \\
38 & 0.4 & 0.39 & 0.98 \\
39 & 0.31 & 0.32 & 1.03 \\
Mean & 0.32 & 0.34 & \\
& & & \\
\hline
\end{tabular}

acoustic tracking removes potential effects of tracking boats on shark behavior.

Another benefit of Crittercam is the ability to observe directly the behavior of a free-swimming shark over a significant time period, allowing important questions of shark foraging to be addressed. Video collected from tiger sharks allowed us to observe both apparent and definite shark foraging behavior in 12 sharks as well as the behavior of both sharks and potential prey during encounters (these data will be presented elsewhere). Feeding behavior has also been observed in 1 Crittercam deployment on white sharks (Marshall 1998).

Intraspecific interactions were not observed during our tiger shark deployments, but this may partially be due to relatively poor water visibility in Shark Bay (usually $<4 \mathrm{~m}$ ). In a white shark video, another white shark gave way to the animal fitted with the Crittercam in response to apparent aggressive displays (Marshall 1998). Studies of sharks that are found in high densities (e.g. Caribbean reef sharks Carcharhinus perezi) or travel in groups (e.g. sevengill sharks Notorynchus cepedianus, Ebert 1991) may benefit from the application of Crittercam technology, as previously unobservable interactions may be recorded, and systematic behavioral studies undertaken.

Besides tiger sharks in this study, Crittercam deployments have been made on white shark Carcharodon

Editorial responsibility: Otto Kinne (Editor), Oldendorf/Luhe, Germany carcharias $(\mathrm{n}=9)$, salmon shark Lamna ditropis $(\mathrm{n}=5)$, nurse shark Ginglymostoma cirratum ( $\mathrm{n}=2$ ), bull shark Carcharhinus leucas $(\mathrm{n}=1)$, and lemon shark ( $\mathrm{n}=1$ ) (Marshall 1998, G. Marshall unpubl. data). Deployments have been made on sharks between approximately $200 \mathrm{~cm}$ total length (TL) (salmon shark) and $405 \mathrm{~cm}$ TL (tiger shark); all have been Hi-8 units. Deployments on smaller sharks (approximately 180 to $200 \mathrm{~cm}$ TL) are now possible with digital units.

Crittercam can provide unique insight into the behavior and ecology of large sharks. It allows investigators to gather accurate data on shark habitat use, swimming depth, and water temperature while providing images of predatory and social behavior. Future studies that incorporate Crittercam technology, especially in areas of good water visibility, will greatly enhance our current understanding of large sharks, and should aid in drafting conservation strategies for these apex predators by helping to define critical foraging habitats and prey species. ${ }^{1}$

Acknowledgements. We would like to thank the National Geographic Special Projects team, especially Derrik Cheung, Medhi Bakhtiari, and Lynne Barre, for providing Crittercam systems and logistical support. Further financial support for fieldwork in Australia was provided by the PADI Foundation, the National Geographic Expedition's Council, and NSERC Canada (Grant A6869 to L.M.D.). This work was conducted under the authority of Fisheries WA permit 69/97, Department of Conservation and Land Management permits SF002347 and NE001808, and Simon Fraser University Animal Care permit. Thanks to Lynne Barre, Colin Simpfendorfer, Michelle Heupel and Ian Hamilton for comments on this manuscript.

\section{LITERATURE CITED}

Ebert DA (1991) Observations of the predatory behaviour of the sevengill shark Notorynchus cepidianus. S Afr J Mar Sci 11:455-465

Heithaus MR (2001) The biology of tiger sharks (Galeocerdo cuvier) in Shark Bay, Western Australia: sex ratio, size distribution, diet, and seasonal changes in catch rates. Environ Biol Fish (in press)

Holland KN, Wetherbee BW, Lowe CG, Meyer CG (1999) Movements of tiger sharks (Galeocerdo cuvier) in coastal Hawaiian waters. Mar Biol 134:665-673

Marshall GJ (1998) Crittercam: an animal-borne imaging and data logging system. Mar Technol Soc J 32:11-17

Morrissey JF, Gruber SH (1993) Habitat selection by juvenile lemon sharks, Negaprion brevirostris. Environ Biol Fish 38:311-319

Parrish FA, Craig MP, Ragen TJ, Marshall GJ, Buhleier BM (2000) Identifying diurnal foraging habitat of endangered Hawaiian monk seals using a seal-mounted video camera. Mar Mamm Sci 16:392-412

\footnotetext{
${ }^{1}$ For information on obtaining Crittercam for research purposes, contact Greg Marshall at gmarshal@ngs.org or camculture@aol.com
}

Submitted: April 10, 2000; Accepted: September 29, 2000

Proofs received from author(s): November 22, 2000 